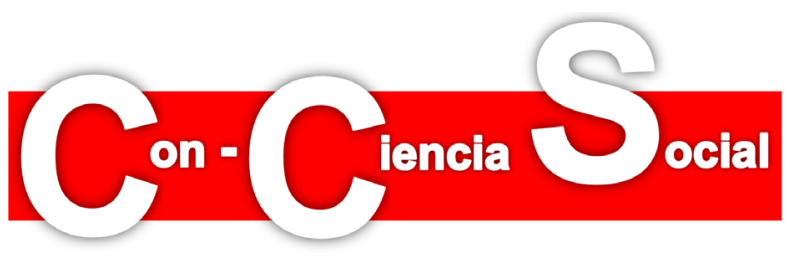

\title{
La utopía frente al Gran Hotel Abismo: reflexiones en torno a la Biografía coral de la Escuela de Frankfurt de Stuart Jeffries
}

\section{The utopia against the Grand Hotel Abyss: reflections on Stuart Jeffries's Frankfurt School choral biography}

\author{
Gustavo Hernández Sánchez \\ Fedicaria-Salamanca \\ gustavohernandezhistoria@gmail.com
}

Recibido en mayo de 2019

Aceptado en mayo de 2019

DOI:10.7203/con-cienciasocial.3.16792

\section{RESUMEN}

El siguiente texto es un apunte crítico en torno a la lectura de la obra de Stuart Jeffries, Gran Hotel Abismo. Biografía coral de la Escuela de Frankfurt. En él se destaca el innegable valor divulgativo y afán polémico del periodista británico para acercar al gran público una cuestión tan compleja como es la introducción de los autores que conforman la Escuela de Frankfurt (desde Th. Adorno y M. Horkheimer, a W. Benjamin, E. Fromm, H. Marcuse o J. Habermas, entre otros). Nos sirve asimismo para reflexionar en torno al contexto histórico que atravesaron todos ellos, especialmente en el intervalo que va de la Gran Guerra al final de la Segunda Guerra Mundial y que ha sido definido por algunos historiadores como "Era de las catástrofes" o "Guerra Civil Europea". También para hacer una valoración en torno al papel del pensamiento crítico y de la propia izquierda después del "fin de las utopías", como uno de los elementos centrales que preconizó esta escuela de pensamiento.

Palabras clave: Escuela de Frankfurt, Era de las catástrofes, Guerra civil europea, fin de las utopías.

\begin{abstract}
The following text is a critical point around the reading of the work of Stuart Jeffries, Gran Hotel Abismo. Choral biography of the Frankfurt School. It highlights the undeniable informative value and controversial zeal of the British journalist to bring to the general public a question as complex as the introduction of the authors that make up the Frankfurt School (from Th. Adorno and M. Horkheimer, to W. Benjamin , E. Fromm, H. Marcuse or J. Habermas, among others). It also serves to reflect on the historical context that they all went through, especially in the interval between the Great War and the end of the Second World War, which has been defined by some historians as the Age of Catastrophes or the European Civil War. Also to make an assessment around the role of the critical thinking and the left political thought after the end of utopias, as one of the central elements advocated by this school.
\end{abstract}

Keywords: Frankfurt School, Era of catastrophes, European Civil War, End of Utopias.

\section{Referencia}

Hernández Sánchez, G. (2020). La utopía frente al Gran Hotel Abismo: reflexiones en torno a la Biografía coral de la Escuela de Frankfurt de Stuart Jeffries. Con-Ciencia Social (segunda época), 3, 127-136. DOI:10.7203/con-cienciasocial.3.16792 
La biografía coral que, sobre la Escuela de Frankfurt, ofrece el periodista del medio de comunicación británico The Guardian, resulta una lectura grata y muy refrescante a pesar de su extensión, sus muchas ironías (de incorregible humor inglés) y su constante afán por exagerar y caricaturizar algunos de sus argumentos. En efecto, vivimos unos tiempos en los que la crónica periodística asalta campos de estudio en otros momentos casi solo reservados al pensamiento especializado. De esta guisa, a lo largo de nada menos que diecisiete capítulos, agrupados en siete partes y más de cuatrocientas páginas, Jeffries aborda la trayectoria de esta escuela de pensamiento que, desde la década de los veinte del siglo pasado hasta (casi) el presente, agrupan la producción, entre otros, de intelectuales de la talla de Walter Benjamin, Theodor Adorno y Max Horkheimer, Eric Fromm, Herbert Marcuse o Jürgen Habermas. Semejante obra no se podía ventilar en pocas páginas. Para iniciar este recorrido, y como hipótesis de trabajo, Jeffries emplea la metáfora utilizada por György Luckács en el prólogo de su Teoría de la novela (1916), escrito en 1962, la cual da título al libro, y por la que el húngaro consideró que:

Gran parte de la intelectualidad alemana más influyente, incluyendo Adorno, se han instalado en el Gran Hotel Abismo, al que describo, en conexión con mi crítica a Schopenhauer [El asalto a la razón, 1954], como <un espléndido hotel, equipado con todas las comodidades, situado al borde de un abismo hacia la nada, hacia el absurdo;; la diaria contemplación de Abismo, entre excelentes platos y entretenimientos artísticos, sólo puede exaltar el disfrute de las comodidades ofrecidas (Lukács, 2010, p. 20).

Quién sabe si tal vez por ello los grandes renovadores del marxismo europeo, creadores del denominado "marxismo cultural", en torno a la imagen dialéctica de la teoría crítica, terminarían sus días devorados de manera fáustica al ser increpados por los estudiantes que, en el mayo del 68, se rebelaban contra toda forma de autoridad, incluida la tradición de la que formaban parte, tal y como habían hecho los filósofos de la Escuela de Frankfurt menos de un siglo antes en relación al marxismo, en lo que el autor cataloga de "confrontación edípica", utilizando términos freudianos. Comprendía este ataque, aunque en menor medida, a uno de los padres de la Nueva Izquierda, Herbert Marcuse ${ }^{1}$. No obstante, entre estos sucesos y los

\footnotetext{
${ }^{1}$ Quien a su vez, en 1969, se había atrevido incluso a criticar a Adorno de traicionar la teoría crítica con su conformismo y conservadurismo (Adorno y Marcuse, 1999, pp. 123-136.). En efecto, el
} 
primeros pasos del Instituto de Investigación Social habían pasado demasiadas cosas. La fecha oficial de su nacimiento es febrero de 1924, a pesar de que su edificio, diseñado por Roeckle, abriese sus puertas en junio de ese mismo año, con el apoyo económico de industriales alemanes. Su primer director fue Carl Günberg, quien desde el principio se apoyó en Friedrich Pollock y Max Horkheimer, su director desde finales de la década de los veinte, momento en que se sumaría su principal fuerza intelectual: Adorno. Entre las vicisitudes del Instituto se encuentra su traslado a Estados Unidos a partir de 1933 durante el paréntesis de la dictadura nacionalsocialista, hasta su regreso en 1951 de nuevo a su lugar de origen, esta vez con un mundo dividido bajo un enfrentamiento de otro signo, caracterizado por el contexto de la Guerra Fría y la división de Alemania tras la Segunda Guerra Mundial. El nuevo contexto internacional exigía unas claves interpretativas distintas. ¿Qué les había llevado a terminar así a estos pensadores marxistas (al menos en sus orígenes)? ¿Realmente se había materializado la crítica que vertiese Lukács en su día, quien consideraba que "la Escuela de Frankfurt había abandonado la necesaria conexión entre teoría y praxis [las cuales han de imbricarse de manera dialéctica]", convirtiendo en buena medida a la "teoría crítica" en "un ejercicio elitista de interpretación"? (Jeffries, 2018, p.12). Según la opinión vertida por el británico desde la introducción: "la Escuela de Frankfurt de la que Adorno era la principal fuerza intelectual veneraba la teoría como el único espacio en el que el orden imperante podía ser inculpado, si no derrocado". Una teoría que, en última instancia, Adorno interpretó como garante de la libertad, y la cual resulta necesariamente melancólica: "ya que nace de una pérdida de la esperanza en un cambio real" (Ibídem, pp. 16-17). No obstante, este acusado pesimismo del alemán se derramaba a partir de una experiencia que nos parece suficientemente traumática como para tomarla en cuenta, la cual preconizaba ya, en clave filosófica, otra ruptura, la que en 1989 anunciaba el quiebre de las utopías de la modernidad, y de la que los filósofos de Frankfurt son, indudablemente, predecesores. Nos parece interesante volver después sobre esta idea de la melancolía en la izquierda y cómo afecta no solamente a las interpretaciones filosóficas al respecto, sino a la propia reflexión en torno al pensamiento político de las izquierdas en el siglo XXI. Además de esto, Jeffries bucea en algunas de las contradicciones que atravesaron a este conjunto de 26). 
filósofos, en su mayoría alemanes, puesto que también, a pesar de todo ello, fueron capaces de desarrollar: "un poderoso aparato crítico para entender la época que atravesaban" (Ibídem, p. 20) e incluso el presente, puesto que, tal y como reconoce el autor, casi al final del libro: "la industria de la cultura ha triunfado en formas que ni siquiera Adorno y Horkheimer hubieran imaginado" (Ibídem, p. 447), dominadas por algoritmos que encapsulan nuestra comprensión de la realidad vía dispositivos electrónicos, redes sociales e Internet, los grandes hermanos de la condición postmoderna. Lo que nos obliga a replantearnos, en última instancia, cuáles pueden ser algunas de las claves del pensamiento utópico hoy. ¿Acaso no pasan irremediablemente por algunas de las conclusiones a las que llegaron los autores de la Escuela de Frankfurt?

Probablemente no se abordaba un estudio de este tipo desde el clásico de Martin Jay (1974), La imaginación dialéctica. No obstante, el trabajo de Jeffries resulta un acercamiento más despegado, menos especializado, quizá también impreciso, pero no por ello menos útil, al menos para aquellos que se quieran introducir por primera vez en el pensamiento de los filósofos de Frankfurt sin aburrirse demasiado en divagaciones filosóficas, pero suficientemente hondo como para comprender su trabajo con seriedad. También para aquellas personas a las que les guste un poco el morbo, por qué no. El libro se lee como un ameno relato en el que entre sus páginas subyace un continuo y constante afán por polemizar y buscar las contradicciones que desacralicen a estos tótems del pensamiento crítico. Así como algunas simplificaciones de carácter historiográfico que podrían dar lugar a equívocos ampliamente reproducidos, por otro lado, cuando no a posibles malentendidos, como el crédito que concede a la idea de la muerte de Walter Benjamin por agentes de Stalin ${ }^{2}$. En nuestra lectura crítica, preferiremos centrarnos más en estos aspectos, en lugar de otros que en algunos pasajes el autor omite $u$ olvida, como puede ser, por ejemplo, la animadversión de Hannah Arendt hacia

\footnotetext{
${ }^{2}$ Siguiendo las indagaciones de Stephen Schwartz (2001), el británico afirma que había agentes de Stalin operando en la frontera franco-española, y que podrían haber acabado con la vida de Benjamin. Argumento que no nos parece suficiente, puesto que también está documentado al menos hasta un agente de la Gestapo en Portbou, el pueblo fronterizo en el que murió. La Gestapo por esos días ya colaboraba estrechamente junto con las autoridades falangistas que acababan de tomar militarmente el pueblo con el fin de deportar judíos y otras personas marcadas en listas negras del partido nacionalsocialista. Son estas autoridades falangistas (el cura Andreu Freixa o el médico Pedro Gorgot, entre otros) quienes parece más probable que estén detrás de la falsificación del acta de defunción de Benjamin, firmada por el médico Ramón Vila Moreno, quien probablemente no estuviese presente el día de su muerte. Toda esta información aparece en el documental de David Mauas (2005), quien trata de demostrar esta otra tesis. Y, a pesar de todo ello, nos parece también muy improbable que la fotógrafa Henny Gurland, esposa de Eric Fromm, quien huía junto con Benjamin y es la única que pudo constatar su suicidio, tuviese ningún interés por ocultar este hecho.
} 
Adorno, quien, al parecer, contribuyó al fracaso académico de su primer marido, el filósofo polaco Günther Anders.

Quizá con cierto abuso del género biográfico (o, más bien, contrabiográfico), se echa en falta una reflexión más profunda del autor en torno al periodo histórico que hubieron de atravesar todos ellos, como si el contexto no fuese decisivo a la hora de ir construyendo todas esas contradicciones que a menudo se señalan, más que los entresijos personales. Así como las condiciones de producción de la obra de muchos de estos autores, fruto de dicho contexto. En efecto, los filósofos de la Escuela de Frankfurt fueron partícipes del derrumbe del viejo siglo XIX, de la barbarie del siglo XX y, en buena medida, también de la caída de las utopías a finales de la modernidad. Tal y como señala el historiador italiano Enzo Traverso, quizá sea el "signo del eclipse de las utopías" lo que configura una "diferencia central (...) que define el Zeigeist de nuestro tiempo" de los dos siglos anteriores (Traverso, 2017, p. 288); cuestión que abordaremos al final de estas páginas. Por el momento, preferiremos centrarnos en ese ciclo histórico que el historiador británico Eric Hobsbawm definió como «siglo veinte cortos, el cual va desde el inicio de la Gran Guerra en 1914 hasta el fin de la era soviética, tras la caída del muro de Berlín, en 1989. Y, entre estos años, un periodo de desastres, catalogado como "era de las catástrofes", que se inicia con la declaración austriaca de guerra contra Serbia el 28 de junio de 1914 y se prolonga hasta la rendición incondicional del Japón el 14 de agosto de 1945 (Hobsbawm, 1995, p. 30.). Intervalo de guerras y de conflictos que se vería atravesado por la Shoah durante la Segunda Guerra Mundial, de la cual ellos y sus familias fueron actores, pero, sobre todo, víctimas. Este periodo configuró las experiencias vitales de todos ellos e irremediablemente sacudió la conciencia de todos los europeos. En efecto, "a partir de 1944", especialmente significativo en el caso de Adorno: "Auschwitz se convirtió en una dimensión central de su pensamiento y su obra" (Traverso, 2019, p. 328.). No se entiende sino de otro modo la publicación en 1944 de Dialéctica de la Ilustración, en la que Adorno y Horkheimer expresan el signo de la "barbarie" que caracteriza el propio concepto de "civilización" y, vinculado a ella, las ideas de "modernidad" y de "progreso". Estas reflexiones, iniciadas en sus orígenes por Walter Benjamin, como precursor de algunas de las preocupaciones centrales que abordaron estos autores, trascendían y sobrepasaban este periodo, puesto que apuntaban en un sentido amplio a las diversas formas de dominación, no sólo dentro del "totalitarismo" nacionalsocialista, por supuesto, sino 
también del soviético o el liberal, todos ellos inmersos en una "razón instrumental" que atraviesa toda la modernidad, y la cual tenía su sociogénesis en el pensamiento ilustrado. Para Adorno y Horkheimer (2007, p.39) la Ilustración era totalitaria como ningún otro sistema. En ella: "el dominio no se paga solo con la alienación de los hombres respecto de los objetos dominados", sino que exige: "la autoalienación de los individuos, que han de amoldarse en cuerpo y alma al aparato técnico" (Ibídem, pp. 43-44). Mientras que en Mínima moralia (1951), Adorno abría este trabajo reflexionando sobre la "ciencia melancólica": "quien quiera conocer la verdad sobre la vida inmediata tendrá que estudiar su forma alienada, los poderes objetivos que determinan la existencia individual hasta en sus zonas más ocultas" (Adorno, 1998, p. 9). Y eso suponía hacerlo bajo cualquier forma de dominación y alienación. Nos parece que en pasajes de este calado es el punto en el que podemos considerar a todos ellos bajo el paraguas del término de "clásicos" del pensamiento, en la medida en que fueron capaces de "〈trascender〉 su tiempo" (Traverso, 2017, p. 23). Mientras que, en el texto de Jeffries se critican, en cambio, cuestiones como que Adorno menospreciase el papel de la Unión Soviética en la derrota de Hitler, afirmando que: "fue el totalitarismo soviético el que asestó el golpe crucial al totalitarismo nazi, no el capitalismo liberal" (Jeffries, 2018, p. 284.). Nos parece que estos debates no son una cuestión central, tan siquiera de interés, en la obra de Adorno. En efecto, al igual que muchos otros autores, como el propio Hobsbawm, Jeffries: "no avanza hasta el punto de localizar las raíces de la barbarie en la propia civilización" (Traverso, 2017, p. 65). La "era de las catástrofes" configuró un periodo que debe ser interpretado más allá de la idea de la lucha del bien contra el mal, tal y como efectivamente nos parece que hicieron los filósofos de Frankfurt. Enzo Traverso, por su parte, aborda el estudio de este periodo bajo el polémico concepto de "guerra civil europea", en la que practica una severa revisión de las famosas tesis de Ernst Nolte que tanto enfadaron a Habermas en la conocida como "querella de los historiadores", la cual se produjo en Alemania entre 1986 y $1987^{3}$. Nolte interpreta el siglo XX como "una época dominada por un conflicto radical (...) entre revolución y contrarrevolución, comunismo y fascismo" (Traverso, 2009: p. 32) a los que define bajo el epíteto de "totalitarismos". De modo que, en lo que cataloga como "era del fascismo", considera "necesario examinar la condición más elemental para la existencia de éste, el

\footnotetext{
${ }^{3}$ Esta se inició debido a una conferencia dictada en Múnich en 1980, cuya versión abreviada se publicó en el Frankfurter Allgemeine Zeitung el mismo año, y el texto completo en 1985 en inglés (Nolte, 1985, pp.17-38).
} 
bolchevismo o comunismo soviético" (Nolte, 1994 [1987], p. 14.). Desvelando así, en opinión de Traverso: "la verdadera fuente del mal, en el bolchevismo" (Traverso, 2009, p. 33). Para Traverso, en cambio, la "guerra civil europea" comprendería más bien un ciclo muchísimo más complejo de "guerras «clásicas) entre estados, revoluciones, guerras civiles, guerras de liberación nacional, genocidios, enfrentamientos violentos surgidos de divisiones de clases, nacionales, religiosas, políticas e ideológicas" (Traverso, 2009, p. 30.). De manera que en su libro $A$ Sangre y fuego. De la guerra civil europea (1914-1945) analiza, configurando una suerte de Libro de los pasajes, la famosa obra inacabada de Walter Benjamin, sobre la que después hablaremos, una anatomía de todos estos años. En definitiva, el historiador italiano, muy en sintonía con algunas de las conclusiones de los filósofos de Frankfurt a los que conoce bien, interpreta este periodo como una regresión del proceso de civilización. De modo que la "guerra civil europea" también incluiría los propios "logros del proceso de civilización":

La monopolización estatal de las armas, la racionalidad administrativa y productiva, la división del trabajo, la fragmentación de las tareas, el autocontrol de las pulsiones, la irresponsabilización ética de los actores sociales, la separación espacial entre ejecutores y víctimas (Ibídem, p. 83).

De lo que resultó un conflicto de aniquilación, el cual tiene muchos y ricos vectores de análisis, desde el acontecimiento central en el que desemboca, como es la Shoah, a las acciones criminales de la Wehrmacht y las SS, el ejército rojo, o los bombardeos aliados sobre Dresde y otras ciudades alemanas, culminando en el lanzamiento de sendas bombas atómicas sobre Hiroshima y Nagasaki, así como un largo y doloroso etcétera. En otras palabras, un conflicto que define unas vastísimas zonas grises y cuyo horizonte en muchos pasajes se pierde de vista en la obra de Jeffries, por ejemplo, a la hora de analizar cómo influyó todo ello en las condiciones de vida y de producción intelectual de los personajes estudiados. Distinto talante muestra a la hora de afrontar algunos autores en cierto sentido periféricos, sobre los que parece esconder mayor simpatía. En especial Walter Benjamin, probablemente porque su propuesta fuese más radical, frente a la, en algunos puntos desesperante, reticencia a generar un programa de acción política por parte de Adorno. Es importante resaltar en este punto la problemática de catalogar a un conjunto tan 
amplio y tan rico de autores siempre bajo la idea de "escuela de pensamiento", como si en todos ellos subyaciese una idea de continuidad, puesto que, tal y como advirtiera Jay (1974, p. 15) en su estudio clásico: "un análisis definitivo de cada uno de ellos requeriría un equipo de estudiosos expertos en todo, desde musicología hasta sinología". Entendemos que la enunciación de escuela debe emplearse más bien como recurso explicativo. Volviendo a Benjamin, nos parece que Jeffries da en el clavo cuando trata de acercarnos la compleja obra de este pensador judío quien, entre otras preocupaciones, a lo largo de trece años desde 1927 hasta su muerte en 1940, trabajó en su Libro de los Pasajes, una obra incompleta que pretendía ser una filosofía de la historia del siglo XIX, compuesta a modo de collage, y, de nuevo, difícil de comprender sin acercarnos al contexto cultural de un periodo en el que la música atonal o las vanguardias artísticas descomponían, o mejor dicho socavaban, los resortes de la modernidad, el viejo siglo $\mathrm{XIX}^{4}$. Este edificio tardó casi un siglo en derrumbarse, y de ello fueron testigos los filósofos alemanes. Probablemente su obra clave sean las conocidísimas tesis "sobre el concepto de historia". Manuscrito entregado a la propia Hannah Arendt antes de su fatal destino en 1940. En ellas, el famoso ángel de la historia (novena tesis), mira hacia el pasado y ve el signo de la catástrofe: "que amontona incansablemente ruina sobre ruina", mientras que desde el paraíso sopla un huracán que irremediablemente le empuja hacia el futuro: "Ese huracán es lo que nosotros llamamos progreso". Consideramos que esta es una de las conclusiones centrales a las que llegó la Escuela de Frankfurt. Tesis que continúa teniendo plena vigencia en el presente. Con todo y con eso, la lectura del libro de Jeffries resulta entretenida hasta el punto de que se puede leer casi como una novela, un logro que actualiza y hace accesible al gran público un estudio de estas características.

Nos detendremos, para terminar, en la idea de "melancolía de la izquierda" con la que abríamos estas breves reflexiones: ¿Qué hay de cierto en esta tesis que hoy sostienen historiadores como Enzo Traverso, indudablemente influido por su conocimiento de los filósofos de Frankfurt y, en especial, del martillo del yunque de la obra de Benjamin? ¿Es la melancolía de la izquierda una verdad autoimpuesta

\footnotetext{
${ }^{4}$ Anotaremos tan sólo otra anécdota que Jeffries no menciona. Por la realización de esta investigación, Benjamin, quien por aquel entonces se encontraba ya exiliado en Francia y con una situación económica bastante frágil, recibió un subsidio mensual de 80 dólares a cargo del Instituto de Investigación Social, instalado en esos años en la Universidad de Columbia (Nueva York). Desde allí, Adorno se preocuparía de tratar de trasladar a Benjamin, quien no pudo soportar la presión de la huida, suicidándose en Portbou.
} 
derivada de la idea de "fin de la historia"? ¿O más bien una certeza que algunos se niegan a admitir retrasando la necesidad de repensar de forma crítica el pensamiento de izquierdas en el siglo XXI, distanciándonos de las catástrofes que marcaron el pasado? Traverso otorga en su último trabajo una dimensión ontológica a esta cuestión. De este modo, considera el término "izquierda" como: "los movimientos que lucharon por cambiar el mundo con el principio de la igualdad en el centro de su programa" (Traverso, 2019, p. 17). Y nos parece que puede tratarse de un buen punto de partida. Más allá de que podamos constatar o no el fin de las utopías (al menos sí de las de aquellas que atravesaron la modernidad), el mundo surgido después de 1989 exige repensarlas no sólo desde la posibilidad, sino más bien desde la necesidad de crear alternativas a la distopía contemporánea, en la que el capitalismo engulle, tal y como preconizó Marx, sus dos fuentes de riqueza: el ser humano y la naturaleza. Tal y como planteaba el crítico literario Fredric Jameson, en un mundo en el que es más fácil imaginar su fin que el fin del capitalismo (reproducimos la cita por su interés):

El problema estriba entonces en cómo localizar una diferencia radical; en cómo arrancar en frío el sentido de la historia para que éste empiece de nuevo a transmitir tenues señales de tiempo, alteridad, cambio, Utopía. El problema que hay que resolver es el de escapar del presente calmo de la posmodernidad para volver al tiempo histórico real y a una historia hecha por seres humanos (Jameson, 2003, p. 103).

\section{REFERENCIAS}

Adorno, Th. W. y Herbert, M. (1999). Correspondence on the German Student Movement, New Left Review, 233, 123-136.

Benjamin, W. (2005). Sobre el concepto de historia. En Obras completas. (pp. 175194). Madrid: Abada.

Hobsbawm, E. (1995). Historia del siglo XX. Barcelona: Crítica.

Horckheimer, M. y Adorno, Th. W. (2007). Dialéctica de la llustración. Fragmentos filosóficos. Madrid: Akal.

Jay, M. (1974). La imaginación dialéctica. Historia de la Escuela de Frankfurt y el Instituto de Investigación Social (1923-1950). Madrid: Taurus.

Jameson, F. (2003). La ciudad futura, New Left Review, 21, 91-106.

Lukács, G. (2010). Teoría de la novela. Un ensayo histórico-filosófico sobre las 
formas de la gran literatura épica. Buenos Aires: Godot.

Mauas, D. (2005). ¿Quién mató a Walter Benjamin? Barcelona: Milagros Producciones.

Nolte, E. (1994). La guerra civil europea, 1917-1945. Nacionalsocialismo y bolchevismo. México: Fondo de Cultura Económica.

Nolte, E. (1985). Between Myth and Revisionism? The Third Reich in the Perspective of the 1980s. In Koch, H.W., Aspects of the Third Reich (pp. 17-38). Palgrave: London.

Schwartz, S. (2001, 11 junio). "The mysterious Death of Walter Benjamin", The Weekly Standard, [entrada noticia]. Recuperado de https://www.weeklystandard.com/stephen-schwartz/the-mysterious-death-ofwalter-benjamin

Traverso, E. (2019). Melancolía de izquierda. Después de las utopías. Barcelona: Galaxia Gutenberg.

Traverso, E. (2017). La historia como campo de batalla. Interpretar las violencias del siglo XX. México: Fondo de Cultura Económica.

Traverso, E. (2009). A sangre y fuego. De la guerra civil europea (1914-1945). Valencia: Univèrsitat de València. 